\title{
Statins and New-Onset Diabetes Mellitus and Diabetic Complications: A Retrospective Cohort Study of US Healthy Adults
}

\author{
Ishak Mansi, M.D. ${ }^{1,2}$, Christopher R. Frei, Pharm.D., M.Sc. ${ }^{3,4}$, Chen-Pin Wang, Ph.D. ${ }^{5}$, and Eric M. \\ Mortensen, M.D., M.Sc. ${ }^{1,2}$ \\ 'Department of Medicine, VA North Texas Health System, Dallas, TX, USA; '2Departments of Medicine and Clinical Sciences, University of Texas \\ Southwestern, Dallas, TX, USA; ${ }^{3}$ Pharmacotherapy Division, College of Pharmacy, The University of Texas at Austin, Austin, TX, USA; \\ ${ }^{4}$ Pharmacotherapy Education and Research Center, School of Medicine, University of Texas Health Science Center, San Antonio, TX, USA; \\ ${ }^{5}$ University of Texas Health Science Center, San Antonio, TX, USA.
}

BACKGROUND: Statin use is associated with increased incidence of diabetes and possibly with increased body weight and reduced exercise capacity. Data on the longterm effects of these associations in healthy adults, however, are very limited. In addition, the relationship between these effects and diabetic complications has not been adequately studied.

OBJECTIVE: To examine the association between statin use and new-onset diabetes, diabetic complications, and overweight/obesity in a cohort of healthy adults.

RESEARCH DESIGN: This was a retrospective cohort study.

PARTICIPANTS: Subjects were Tricare beneficiaries who were evaluated between October 1, 2003 and March 1, 2012. Patients were divided into statin users and nonusers.

INTERVENTION: We excluded patients who, at baseline, had a preexisting disease indicative of cardiovascular diseases, any positive element of the Charlson comorbidity index (including diabetes mellitus), or life-limiting chronic diseases. Using 42 baseline characteristics, we generated a propensity score to match statin users and nonusers.

MAIN MEASURES: Outcomes assessed included newonset diabetes, diabetic complications, and overweight/ obesity.

KEY RESULTS: A total of 25,970 patients (3982 statin users and 21,988 nonusers) were identified as healthy adults at baseline. Of these, 3351 statins users and 3351 nonusers were propensity score-matched. Statin users had higher odds of new-onset diabetes (odds ratio [OR] 1.87; $95 \%$ confidence interval [95 \% CI] 1.67-2.01), diabetes with complications (OR 2.50; 95\% CI 1.88-3.32), and overweight/obesity (OR 1.14; $95 \%$ CI 1.04-1.25). Secondary and sensitivity analyses demonstrated similar findings.

CONCLUSIONS: Diabetes, diabetic complications, and overweight/obesity were more commonly diagnosed among statin-users than similar nonusers in a healthy cohort of adults. This study demonstrates that short-term

Received October 3, 2014

Revised February 26, 2015

Accepted March 27, 2015

Published online April 28, 2015 clinical trials might not fully describe the risk/benefit of long-term statin use for primary prevention.

KEY WORDS: Overweight/obesity; Diabetes; Diabetic complications; Adverse events; Observational study; Satins; Primary prevention.

J Gen Intern Med 30(11): 1599-610

DOI: $10.1007 / \mathrm{s} 11606-015-3335-1$

(C) Society of General Internal Medicine 2015

\section{INTRODUCTION}

Despite their effectiveness in lowering cardiovascular morbidity and mortality, statins (3-hydroxy-3-methylglutaryl-coenzyme A reductase [HMGR] inhibitors) have been shown to be associated with a small risk of incident diabetes mellitus. ${ }^{1} \mathrm{~A}$ recent cross-sectional study noted higher caloric and fat intake and increased body mass index among statin users in contrast to nonusers. ${ }^{2}$ Additionally, achieving a "cholesterol goal" through swallowing a tablet might result in false self assurance, and may encourage poor dietary choices and a sedentary lifestyle. ${ }^{3}$ Several randomized trials and observational studies have noted that statin users have higher hemoglobin $[\mathrm{Hb}] \mathrm{A}_{1 \mathrm{C}}$ and fasting plasma glucose measurements than nonusers. ${ }^{4-8}$ Hence, it can be surmised that statins may increase the risk of diabetic complications.

Most studies reporting an increased risk of new-onset diabetes among statin users included high-risk populations ${ }^{1}$; data are limited regarding incident diabetes risk in healthy populations. For example, patients in the Anglo-Scandinavian Cardiac Outcomes Trial-Lipid Lowering Arm (ASCOT-LLA) study had hypertension and three or more cardiovascular risk factors. ${ }^{9}$ The Antihypertensive and Lipid-Lowering Treatment to Prevent Heart Attack Trial (ALLHAT-LLT) ${ }^{10}$ West of Scotland Coronary Prevention Study (WESCOPS), ${ }^{11}$ and ASCOT-LLA studies actually included patients who had evidence of preexisting cardiovascular disease $(8,14.2$, and $18.5 \%$, respectively). As a result, some investigators have proposed that statin use is associated with incident diabetes only in the highest-risk population. ${ }^{12}$ 
The objective of this study was to examine the association between statin use and new-onset diabetes, diabetes with complications, and overweight/obesity in a propensity score-matched "healthy" cohort of statin users and nonusers.

\section{RESEARCH DESIGN AND METHODS}

\section{Study Design}

This study was approved by the institutional review boards at Brooke Army Medical Center and the VA North Texas Health Care System, and was a retrospective cohort study of patients enrolled in the San Antonio Military Area as Tricare Prime/ Plus. Tricare is a US health care program for almost 9.5 million beneficiaries worldwide - including active duty service members, national guard and reserve members, retirees, their families, survivors, certain former spouses, and others registered in the US Department of Defense enrollment eligibility reporting system. ${ }^{13}$ We extracted archival data from October 1, 2003 to March 1, 2012, which encompassed administrative, clinical, and financial data, regardless of pointof-care location or affiliation. ${ }^{14}$ Data included outpatient and inpatient electronic medical records, medical benefits claims data, laboratory data performed within the military system, and pharmacy data. Pharmacy data included details of dispensed medications regardless of pharmacy location or affiliation. The reliability and reproducibility of Tricare data have been previously described. ${ }^{13}$

The study was divided into two periods: 1) a baseline period (October 1, 2003 to September 30, 2005), which was used for description of baseline characteristics; and 2) a follow-up period (October 1, 2005 to March 1, 2012), which was used to capture outcome events. All patients were enrolled in the system throughout the study period; hence, there were no missing data.

\section{Patient Population}

Inclusion Criteria. The study included all patients aged 30 to 85 years who were enrolled in the San Antonio area and who met the following criteria:

1. Were enrolled in Tricare Prime/Plus throughout the study.

2. Had at least one outpatient visit during the baseline period and one outpatient visit during the follow-up period.

3. Received at least one prescription medication during the baseline period.

\section{Exclusion Criteria.}

- Trauma and burn patients (based on International Classification of Diseases, Ninth Revision, Clinical Modification [ICD-9-CM] codes), as defined by the
Agency for Health Research and Quality Clinical Classifications Software (AHRQ-CCS), category 240, ${ }^{15}$ and previous publications. ${ }^{16}$

- Patients who were newly started on statins after September 30, 2005 (end of baseline period). This exclusion allowed the creation of statin user and nonuser groups with similar periods of follow-up.

- Patients who received statins for less than 90 days.

To identify a healthy cohort who used statins for primary prevention and without severe comorbidities, we excluded patients with the following diseases:

1. Patients who had any positive elements of the Charlson comorbidity index at baseline using Deyo's method. ${ }^{17}$

2. Patients with ICD-9-CM codes that suggested the presence of cardiovascular disease or their equivalents at baseline as defined by several AHRQ-CCS disease categories (Appendix A).

3. Patients with ICD-9-CM codes for comorbid conditions that might limit life expectancy or physical activity, as defined by the following AHRQ-CCS disease categories $^{15}$ : chronic obstructive pulmonary disease and bronchiectasis; respiratory failure, insufficiency, arrest in adult; nephritis, nephrosis, renal sclerosis; chronic kidney disease; rheumatoid arthritis and related disease; systemic lupus erythematosus and connective tissue disorders; pathological fracture; schizophrenia and other psychotic disorders; or suicide and intentional self-inflicted injury (Appendix A).

We identified two treatment groups:

1. Statin users: patients who filled a statin for at least 90 days between October 1, 2004 and September 30, 2005. This group was further classified as either:

a. High-intensity statin users: patients who were prescribed high-intensity statin therapy, as defined by the guidelines of the American College of Cardiology/American Heart Association (ACC/ AHA), ${ }^{18}$ at any time during the study.

b. Moderate/low-intensity statin users: patients who did not receive high-intensity statin therapy over the duration of the study. ${ }^{18}$

2. Nonusers: patients who did not receive statins at any time during the study.

\section{Outcomes}

We utilized pre-specified diagnosis groups to define our outcomes, as follows:

1. Diabetes mellitus: as identified in AHRQ-CCS category 49 (diabetes mellitus without complications), excluding $\mathrm{V}$ codes signifying preexisting conditions (Appendix B). ${ }^{15}$ 
2. Diabetes mellitus with complications: as identified in AHRQ-CCS category 50 (Appendix B) ${ }^{15}$

3. Overweight/obesity: included selected ICD-9-CM diagnosis codes from category 56 of the AHRQ-CCS (other nutritional; endocrine disorders; metabolic) related to overweight, obesity, and hyperalimentation (Appendix B).

AHRQ-CCS is a diagnosis and procedure categorization scheme that is based on ICD-9-CM codes in which meaningful categories of disease diagnoses are created to enable more useful identification of populations for relatively specific conditions. ${ }^{15}$ The method of creation and validation of AHRQ-CCS was previously published. ${ }^{19-23}$ AHRQ-CCS disease categories have been widely used in numerous publications to identify comorbidities and outcomes, ${ }^{24-29}$ predict mortality, ${ }^{30,31}$ and estimate utilization and costs. ${ }^{32-35}$ AHRQ-CCS disease categories are recognized by the Department of Defense Military Health System and are incorporated into Tricare data as an industry standard. ${ }^{13}$

AHRQ-CCS category 49 (diabetes without complication) and category 50 (diabetes with complications) have been used in clinical research ${ }^{36,37}$ and to generate reports on utilization and cost statistics in relation to diabetes and diabetic complications in various health care settings. ${ }^{38-42}$ Additionally, ICD9 codes have been widely used to ascertain outcomes of "diabetes mellitus" and "diabetes mellitus with complications," as these two outcomes are essential components in calculating the Charlson comorbidity index using Dyeo's method ${ }^{17}$ and the Elixhauser comorbidity score ${ }^{43}$ from administrative data, and both of these scores are widely used. ${ }^{44}$ The sensitivity and specificity of ICD-9 codes for diagnosing diabetes without complications were 77.7 and $98.4 \%$, and for diabetes with complications were 63.6 and $98.9 \%$, respectively. ${ }^{45}$ In a study using the VA database, the sensitivity and specificity of ICD-9 codes in comparison to chart review to identify diabetes were 78.3 and $95.7 \%$, respectively. ${ }^{46}$

The use of ICD-9 codes in general and AHRQ-CCS codes in particular in order to extract obesity diagnoses has been described in the literature ${ }^{47-50}$; AHRQ-CCS codes for obesity have also been used to generate reports on utilization and cost statistics in relation to obesity. ${ }^{51-53}$ In general, the use of ICD-9 codes to identify obesity has been noted as having low sensitivity but high specificity ${ }^{45,54}$; using chart review as the gold standard, the sensitivity, specificity, positive predictive value, and negative predictive value were $24.6 \%, 99.3 \%, 75.9 \%$, and $93.6 \%{ }^{45}$

\section{Data and Statistical Analyses}

In the present study, patients' comorbidities were identified using ICD-9-CM codes (Appendix B and Appendix C), and their Charlson comorbidity index was calculated using Deyo's method. ${ }^{17}$ Using propensity scores, we matched statin users to similar nonusers using 42 variables (Table 1). ${ }^{55}$
Propensity Score Matching. We used a logistic regression model to create the propensity score and test the balance of covariates. ${ }^{56}$ We performed 1:1 nearest neighbor matching with a caliper of $0.01 .^{57}$

Primary Analysis. We examined risks of outcomes in statin users and nonusers in the propensity score-matched cohort using conditional logistic regression analysis.

Secondary and Sensitivity Analyses. Table 2 summarizes the study cohorts and statistical methods. We examined risks of outcomes in the following cohorts using multivariable logistic regression with adjustment for propensity score:

1. Healthy cohort: this cohort included all 25,970 patients in the study population, not just those who were propensity score-matched. Four comparisons were made to assess the risks of outcomes:

a. Statin users (3982 patients) versus nonusers $(21,988$ patients).

b. High-intensity statin users (1155 patients) versus nonusers $(21,988$ patients).

c. Two-year statin users (3308 patients) versus nonusers (21,988 patients).

d. $\quad$ Four-year statin users (2933 patients) versus nonusers (21,988 patients).

2. Overweight/obesity incident cohort: This cohort included only those patients in the "healthy cohort" who did not have a diagnosis of overweight/obesity at baseline. One comparison was made to assess the risk of outcomes:

a. Statin users (3415 patients) versus nonusers $(20,176$ patients).

3. Statin-user cohort: This cohort included only those 3982 statin users from the "healthy cohort." One comparison was made to assess the risks of outcomes:

a. High-intensity statin users (1155 patients) versus moderate/low-intensity statin users (2827 patients).

Baseline characteristics for comparator groups were assessed using chi-square for categorical variables and the Student's $t$ test for continuous variables. Comparisons were considered to be statistically significant at $p$ values $\leq 0.05$. Statistical analyses were performed using Stata software (Version 12; StataCorp LP, College Station, TX, USA) and SPSS software (Version 19; IBM Corp., Armonk, NY, USA).

\section{RESULTS}

Based on our initial inclusion and exclusion criteria, 43,438 patients were identified $(13,626$ statin users and 29,812 nonusers). To develop the healthy cohort, we excluded 13,311 subjects with any positive elements in their Charlson 
Table 1 Baseline Characteristics of Propensity Score-Matched Satin Users and Nonusers

\begin{tabular}{|c|c|c|c|}
\hline & $\begin{array}{l}\text { Statin nonusers no. }(\%) \\
(n=3351)\end{array}$ & $\begin{array}{l}\text { statin users no. }(\%) \\
(n=3351)\end{array}$ & $P$ value \\
\hline Age in years, mean \pm SD & $53 \pm 11$ & $53 \pm 11$ & 0.72 \\
\hline Female sex & $1285(38.3)$ & $1314(39.2)$ & 0.48 \\
\hline Smoking & $241(7.2)$ & $237(7.1)$ & 0.89 \\
\hline Alcohol-related disorders & $29(0.9)$ & $31(0.9)$ & 0.80 \\
\hline Substance-related disorders & $12(0.4)$ & $8(0.2)$ & 0.38 \\
\hline \multicolumn{4}{|l|}{ Comorbidities in baseline period } \\
\hline Charlson comorbidity score, mean (SD) & $0(0.0)$ & $0(0.0)$ & \\
\hline Overweight/obese & 493 (14.7) & $455(13.6)$ & 0.19 \\
\hline Hypertension $^{\mathrm{b}}$ & $1704(50.9)$ & $1678(50.1)$ & 0.54 \\
\hline Acute kidney injury & $5(0.1)$ & $5(0.1)$ & 1.0 \\
\hline Asthma ${ }^{b}$ & $102(3.0)$ & $96(2.9)$ & 0.71 \\
\hline Gastrointestinal hemorrhage & $118(3.5)$ & $108(3.2)$ & 0.27 \\
\hline Gastritis/duodenitis & $61(1.8)$ & $68(2.0)$ & 0.59 \\
\hline Nonspecific chest pain ${ }^{\mathrm{c}}$ & $301(9.0)$ & $326(9.7)$ & 0.31 \\
\hline Heart disease not otherwise specified ${ }^{\mathrm{c}}$ & $18(0.5)$ & $15(0.4)$ & 0.73 \\
\hline Osteoarthritis, arthropathy, and back disorder & $1534(45.8)$ & $1548(46.2)$ & 0.75 \\
\hline Sprains, strains, and trauma-related joint disorders & $596(17.8)$ & $603(18)$ & 0.85 \\
\hline Fracture of bone & $103(3.1)$ & $110(3.3)$ & 0.68 \\
\hline Osteoporosis & $132(3.9)$ & $112(3.3)$ & 0.22 \\
\hline Rehabilitation care, fitting of prostheses, and adjustment of devices & $506(15.1)$ & $544(16.2)$ & 0.21 \\
\hline \multicolumn{4}{|l|}{ Health care utilization at baseline } \\
\hline Number of inpatient admissions during baseline period, mean \pm SD & $0.08 \pm 0.3$ & $0.08 \pm 0.3$ & 0.82 \\
\hline Number of outpatient medical encounters during baseline period, mean $\pm \mathrm{SD}$ & $21.1 \pm 22.7$ & $21.1 \pm 19.1$ & 0.97 \\
\hline Number of encounters for immunization during baseline period, mean \pm SD & $0.40 \pm 1.1$ & $0.42 \pm 1.14$ & 0.37 \\
\hline Receive immunization and screening for infectious disease & $643(19.2)$ & $670(20)$ & 0.41 \\
\hline \multicolumn{4}{|l|}{ Medications at baseline } \\
\hline Beta-blocker & $428(12.8)$ & $459(13.7)$ & 0.28 \\
\hline Diuretic & $728(21.7)$ & $742(22.1)$ & 0.71 \\
\hline $\mathrm{ACE} / \mathrm{ARB}$ & $886(26.4)$ & $899(26.8)$ & 0.72 \\
\hline Calcium channel blocker & $384(11.5)$ & $395(11.8)$ & 0.70 \\
\hline Proton pump inhibitor & $861(25.7)$ & $863(25.8)$ & 0.98 \\
\hline Aspirin & $777(23.2)$ & $826(24.6)$ & 0.16 \\
\hline NSAID & $1911(57.0)$ & $1926(57.5)$ & 0.73 \\
\hline Bisphosphonate & $215(6.4)$ & $201(6.0)$ & 0.50 \\
\hline Sedatives & $519(15.5)$ & $525(15.7)$ & 0.84 \\
\hline SSRI & $441(13.2)$ & 456 (13.6) & 0.62 \\
\hline Antipsychotic & $30(0.9)$ & $26(0.8)$ & 0.69 \\
\hline Tricyclic anti-depressants & $7(0.2)$ & $5(0.1)$ & 0.77 \\
\hline Systemic corticosteroid & $63(1.9)$ & $72(2.1)$ & 0.49 \\
\hline Hormone replacement therapy & $436(13.0)$ & $420(12.5)$ & 0.58 \\
\hline Testosterone & $15(0.4)$ & $14(0.4)$ & 1.0 \\
\hline Cytochrome p450 & $182(5.4)$ & $193(5.8)$ & 0.60 \\
\hline Non-statin lipid lowering drugs & $194(5.8)$ & $217(6.5)$ & 0.26 \\
\hline Oral hypoglycemic & $16(0.5)$ & $16(0.5)$ & 1.0 \\
\hline Antiplatelet agents (other than aspirin) & $10(0.3)$ & $13(0.4)$ & 0.68 \\
\hline Warfarin & $16(0.5)$ & $14(0.4)$ & 0.86 \\
\hline
\end{tabular}

ACE/ARB angiotensin receptor blockers and angiotensin-converting-enzyme inhibitors, Cytochrome 4450 medications that inhibit the cytochrome $p 450$ system as identified in a recent FDA warning, ${ }^{55}$ HIV human immunodeficiency virus, NSAID non-steroidal anti-inflammatory drugs, SD standard deviation, SSRI selective serotonin reuptake inhibitors

${ }^{a}$ Diagnosis is based on ICD-9-CM codes as identified in the Deyo method for applying the Charlson comorbidity score ${ }^{17}$

${ }^{b}$ We included patients with hypertension but excluded those with hypertension with complications, secondary hypertension, or end-organ damage. Similarly, we included patients with asthma but excluded those with chronic obstructive pulmonary disease, bronchiectasis, respiratory failure, or insufficiency as detailed in the "Research Design and Methods" section

${ }^{c}$ Although these patients had no other diagnosis codes indicative of cardiovascular disease, they were more likely to be seen by cardiologists and to be started on statin therapy; therefore, we included these baseline characteristics in the propensity score matching

comorbidity index, 3876 subjects with diagnoses suggestive of cardiovascular disease, and 281 patients with other comorbidities that might limit life expectancy or physical activity at baseline (Fig 1). Hence, our final healthy cohort included 25,970 patients (3982 statin users and 21,988 nonusers). Overall, $77 \%$ of prescriptions of statins were for simvastatin, $19 \%$ for atorvastatin, $3 \%$ for pravastatin, and $1 \%$ for rosuvastatin. Table 3 describes selected characteristics of the population that met the study criteria. Statin users were older, had higher proportions of men and smokers, had a higher prevalence of comorbidities, and utilized other classes of medications more frequently except for non-steroidal antiinflammatory drugs and testosterone therapy.

\section{Propensity Score-Matched Analysis}

Using propensity scores, we matched 3351 statin users to 3351 nonusers. After matching, there were no significant differences in baseline characteristics between groups (Table 1). In the propensity score-matched cohort (primary analysis), the mean (SD) cumulative duration of statin use among statin users was as follows: mean $(\mathrm{SD})=2001$ (895) days, median 
Table 2 Cohort Groups and Study Methods

\begin{tabular}{|c|c|c|c|c|}
\hline Cohort name & Cohort description & $\begin{array}{l}\text { Covariates } \\
\text { included in } \\
\text { analysis }\end{array}$ & $\begin{array}{l}\text { Number of } \\
\text { statin nonusers }\end{array}$ & $\begin{array}{l}\text { Number of } \\
\text { statin users }\end{array}$ \\
\hline \multicolumn{5}{|l|}{ Primary analysis } \\
\hline Propensity score-matched cohort & $\begin{array}{l}\text { Pairs of statin users and nonusers were } \\
\text { matched based on propensity score }\end{array}$ & $\begin{array}{l}\text { None, since cohort } \\
\text { groups were matched } \\
\text { with no imbalance }\end{array}$ & 3351 & 3351 \\
\hline \multicolumn{5}{|l|}{ Secondary and sensitivity analyses } \\
\hline Healthy cohort & $\begin{array}{l}\text { Healthy individuals who met the inclusion } \\
\text { and exclusion criteria }\end{array}$ & Propensity score & 21,988 & 3982 \\
\hline High-intensity statin-user cohort & $\begin{array}{l}\text { A subset of the "healthy cohort," } \\
\text { restricting statin users to those who used } \\
\text { high-intensity statins at any point of } \\
\text { their follow-up }\end{array}$ & Propensity score & 21,988 & 1155 \\
\hline Two-year statin-user cohort & $\begin{array}{l}\text { A subset of the "healthy cohort," after } \\
\text { excluding statin users who used statins for less } \\
\text { than } 2 \text { years }\end{array}$ & Propensity score & 21,988 & 3308 \\
\hline Four-year statin-user cohort & $\begin{array}{l}\text { A subset of the "healthy cohort," after } \\
\text { excluding statin users who used statins for less } \\
\text { than } 4 \text { years }\end{array}$ & Propensity score & 21,988 & 2933 \\
\hline Overweight/obesity incident cohort & $\begin{array}{l}\text { A subset of the "healthy cohort," after } \\
\text { excluding patients who were diagnosed in the } \\
\text { baseline period with overweight/obesity }\end{array}$ & Propensity score & 20,176 & 3415 \\
\hline $\begin{array}{l}\text { High-intensity statin users } \\
\text { among statin users only }\end{array}$ & $\begin{array}{l}\text { All statin users only in the "healthy cohort," } \\
\text { comparing outcomes between high-intensity } \\
\text { statin users and moderate/low-intensity statin } \\
\text { users }\end{array}$ & Propensity score & None included & 3982 \\
\hline
\end{tabular}

(interquartile range $)=2170(1350-2775)$ days. At some point during the study period, $28 \%$ of statin users received a highintensity statin and $87 \%$ received a moderate-intensity statin. ${ }^{18}$

\section{Primary Analysis}

In the propensity score-matched cohort, statin users had higher ORs for diabetes (OR 1.87; $95 \%$ confidence interval [95\% CI] 1.67-2.01), diabetes with complications (OR 2.50; $95 \%$ CI 1.88-3.32), and overweight/obesity (OR 1.14; $95 \%$ CI 1.04-1.25) (Table 4). Table 5 describes the breakdown of diabetes complications.

During the follow-up period, the mean (SD) number of inpatient admissions for nonusers and statin users were 0.46 (1.19) and 0.45 (1.07), respectively $(p=0.7)$; and the mean (SD) of number of outpatient medical encounters for nonusers and statin users were 60.80 (61.6) and 65.8 (58.9), respectively $(p=0.001)$. Since statin users had more visits with providers than nonusers, we repeated the analysis introducing the number of inpatient admission and outpatient medical encounters during the follow-up period as covariates in the regression model to account for any possible ascertainment bias. Our results continued to be significant; statin users had higher ORs for diabetes (OR 1.85; $95 \%$ CI 1.65-2.07), diabetes with complications (OR 2.53; $95 \%$ CI 1.90-3.38), and overweight/ obesity (OR 1.12; $95 \%$ CI 1.02-1.23).

\section{Secondary and Sensitivity Analyses}

The adjusted ORs for high-intensity statin users were higher than moderate/low-intensity statin users (Table 6). The adjusted ORs for the secondary and sensitivity analyses were higher for statin users across all groups for all outcomes (Table 7). The ORs were highest among high-intensity statin-user cohort.

\section{DISCUSSION}

This study demonstrated that statin use was associated with an increased likelihood of new diagnoses of diabetes mellitus, diabetic complications, and overweight/obesity. Whereas the increased risk of diabetes with statins is well known, the increased risk of diabetic complications has not been previously described.

The overall proportion of patients who developed diabetes during the follow-up period was approximately $14 \%$, which is similar to recent national trends. ${ }^{58}$ The increased risk of diabetes among statin users is well described in several studies. ${ }^{1,59}$ In a meta-analysis of 13 statin clinical trials (mean follow-up duration from 1.9 to 6 years), the OR of incident diabetes was 1.09 (95\% CI 1.02-1.17). ${ }^{1}$ However, these trials used different methods for diagnosing diabetes, and some trials were missing diabetes incidence data. Moreover, all statin primary prevention trials used intention-to-treat analysis, despite high rates of dropout or quitting the study medication (12-33\%), which can result in underestimation of side effects. ${ }^{60}$ Both lipophilic and hydrophilic statins were associated with a similar risk of diabetes, ${ }^{1}$ although other studies have noted that the risk varied with different types of statins. ${ }^{61}$ In a secondary analysis of the Women's Health Initiative data, statin use was associated with an increased risk of diabetes (adjusted hazard ratio [HR] 1.48; $95 \%$ CI 1.38-1.59). ${ }^{62}$ Other 


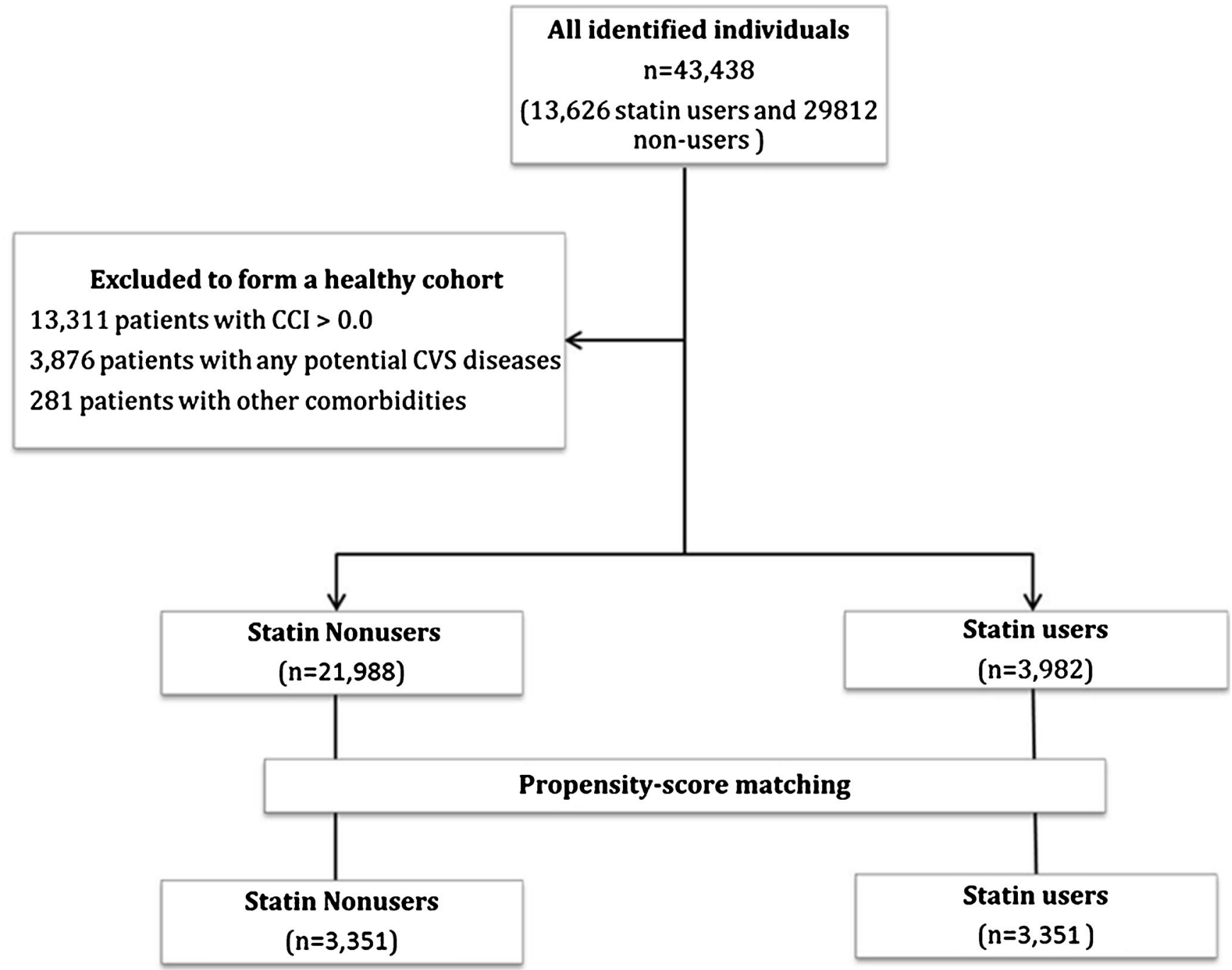

\section{$\mathrm{CCI}=$ Charlson Comorbidity Index; $\mathrm{CVS}=$ Cardiovascular}

Fig. 1 Study cohort

observational studies have noted higher adjusted risk of incident diabetes among statin users versus nonusers. ranging from 2.8 to $4.7 .^{63,64}$

Importantly, our study demonstrated that high-intensity statin therapy was associated with the highest risk of diabetes, diabetic complications, and overweight/obesity (adjusted OR $2.55,3.68$, and 1.58 , respectively), thereby demonstrating a dose-response relationship. A recent observational study ${ }^{59}$ and a meta-analysis of five clinical trials (32,752 patients) noted that higher-potency statins were also associated with a higher risk of diabetes compared to lower-potency statins. ${ }^{65}$

In this study, our intent was to examine the risk of outcomes in a healthy population, excluding patients who had ischemic heart diseases or their equivalents, patients with any Charlson comorbidity (which include renal failure, mild liver disease, HIV, and any malignancy other than skin cancers), and patients with any chronic disease that might limit life expectancy or physical activity (including rheumatologic diseases, psychosis, and prior suicide attempts). In contrast, a meta-analysis of statin use and the risk of incident diabetes included patients with several comorbidities, including prior cardiovascular diseases, peripheral vascular diseases, heart failure, and elevated C-reactive protein (CRP). ${ }^{1}$ Therefore, our study adds a new perspective to the association between statins and risk of incident diabetes.

The association between the use of statins and diabetic complications has not been reported thus far, and deserves further study. In a recent nested matched study of a Danish population, 15,679 statin users were matched to 47,037 nonusers on the basis of sex, age at diabetes diagnosis, year of diabetes diagnosis, and history of cardiovascular disease ${ }^{66}$; the median follow-up was 2.7 years (range $0-13$ ). The study noted that statin users had lower cumulative incidence of diabetic retinopathy (HR $0.60 ; 95 \%$ CI $0.54-0.66$ ) and 
Table 3 Selected Baseline Characteristics of the Healthy Cohort of Statin Users and Nonusers

\begin{tabular}{|c|c|c|c|}
\hline & $\begin{array}{l}\text { Statin nonusers no. }(\%) \\
(n=\mathbf{2 1}, \mathbf{9 8 8})\end{array}$ & $\begin{array}{l}\text { statin users no. }(\%) \\
(n=3982)\end{array}$ & $P$ value \\
\hline Age (years), mean $\pm \mathrm{SD}$ & $42.6 \pm 9.8$ & $54.4 \pm 11.7$ & $<0.001$ \\
\hline Female sex, & $9915(45.1)$ & $1520(38.2)$ & $<0.001$ \\
\hline \multicolumn{4}{|l|}{ Comorbidities in baseline period } \\
\hline Smoking & $1062(4.8)$ & $304(7.6)$ & $<0.001$ \\
\hline Overweight/obese & $1812(8.2)$ & $567(14.2)$ & $<0.001$ \\
\hline Hypertension & $3116(14.2)$ & $2252(56.6)$ & $<0.001$ \\
\hline 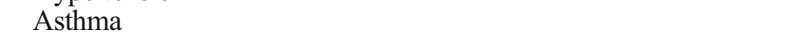 & $625(2.8)$ & $115(2.9)$ & 0.88 \\
\hline Osteoarthritis, arthropathy, or back disorder & $8097(36.8)$ & $1919(48.2)$ & $<0.001$ \\
\hline Osteoporosis & $258(1.2)$ & $149(3.7)$ & $<0.001$ \\
\hline \multicolumn{4}{|l|}{ Health care utilization at baseline } \\
\hline Number of inpatient admissions during baseline period: mean \pm SD & $0.10 \pm 0.37$ & $0.09 \pm 0.34$ & 0.006 \\
\hline Number of outpatient medical encounters during baseline & $17.1 \pm 18.1$ & $22.1 \pm 19.9$ & $<0.001$ \\
\hline period: mean \pm SD & & & \\
\hline $\begin{array}{l}\text { Number of encounters for immunization during baseline } \\
\text { period: mean } \pm S D\end{array}$ & $0.57 \pm 1.4$ & $0.41 \pm 1.1$ & $<0.001$ \\
\hline \multicolumn{4}{|l|}{ Medications at baseline } \\
\hline Beta-blocker & $822(3.7)$ & $650(16.3)$ & $<0.001$ \\
\hline Diuretic & $1495(6.8)$ & $1008(25.3)$ & $<0.001$ \\
\hline $\mathrm{ACE} / \mathrm{ARB}$ & $1431(6.5)$ & $1260(31.6)$ & $<0.001$ \\
\hline Calcium channel blocker & $652(3.0)$ & $566(14.2)$ & $<0.001$ \\
\hline Proton pump inhibitor & $2,915(13.3)$ & $1140(28.6)$ & $<0.001$ \\
\hline Aspirin & $1083(4.9)$ & $1268(31.8)$ & $<0.001$ \\
\hline NSAID & $13,272(60.4)$ & $2288(57.5)$ & 0.001 \\
\hline Bisphosphonate & $475(2.2)$ & $272(6.8)$ & $<0.001$ \\
\hline SSRI & $2336(10.6)$ & $578(14.5)$ & $<0.001$ \\
\hline Hormone replacement therapy & $1,532(7.0)$ & $478(12.0)$ & $<0.001$ \\
\hline Testosterone & $41(0.2)$ & $19(0.1)$ & 0.002 \\
\hline Oral hypoglycemic & $61(0.3)$ & $22(0.6)$ & 0.009 \\
\hline Warfarin & $39(0.2)$ & $21(0.5)$ & $<0.001$ \\
\hline Mean LDL-C in mg/dL during baseline period: $\operatorname{mean} \pm \mathrm{SD}^{\text {a }}$ & $112 \pm 26$ & $122 \pm 33$ & $<0.0001$ \\
\hline Mean HDL-C in mg/dL during baseline period: $\operatorname{mean} \pm$ SD a & $58 \pm 17$ & $54 \pm 15$ & $<0.0001$ \\
\hline
\end{tabular}

ACE/ARB angiotensin receptor blockers and angiotensin-converting-enzyme inhibitors, AHRQ-CSS Agency for Health Research and Quality Clinical Classifications Software, ${ }^{15}$ NSAID non-steroidal anti-inflammatory drugs, SD standard deviation, SSRI selective serotonin reuptake inhibitors

${ }^{a}$ Lipid measurements represent the mean value for each patient throughout the baseline period; these laboratory measurements were only available in 1946 statin users and 3455 nonusers. Lipid measurements were not included in propensity score matching

diabetic neuropathy (HR 0.66; $95 \%$ CI 0.57-0.75), but not diabetic nephropathy (HR 0.97; $95 \%$ CI 0.85-1.10). In contrast, our study had a much longer follow-up period (6.5 years), included only healthy adults without prior cardiovascular diseases, and matched patients on 42 variables including 20 different classes of medications.

Two small trials reported that statins were associated with an improvement in diabetic retinopathy in diabetic patients. ${ }^{67,68}$ For example, in one of the studies, which was a randomized controlled trial (50 patients with diabetic retinopathy), simvastatin was associated with improved ophthalmologic fundus examination. ${ }^{68}$ On the other hand, several observational and experimental studies have noted that statin use was associated with high blood glucose levels. ${ }^{4-8}$

The overall proportion of overweight/obesity in our cohort was high (exceeding $40 \%$ ), but is commensurate with recent estimates of overweight/obesity. ${ }^{69}$ Evidence from in vitro studies indicates that statins can increase body and liver fat accumulation. ${ }^{70} \mathrm{~A}$ recent prospective study noted that, compared to nonusers, statin users expended less metabolic equivalents, engaged in less moderate physical activity and for shorter durations, and exhibited more sedentary behavior for more minutes per day. ${ }^{71}$ In the Justification for the Use of Statins in Primary Prevention: An Intervention Trial Evaluating Rosuvastatin (JUPITER) trial, an increase in body weight was observed among patients in the rosuvastatin group as compared with the placebo group $(0.44 \mathrm{~kg}$ vs $0.15 \mathrm{~kg}$, respectively). ${ }^{72}$ A cross-sectional study (27,886 adults) from the National Health and Nutrition Examination Survey (NHANES) noted that caloric intake, fat intake, and body mass index were higher in statin users compared to nonusers. ${ }^{2}$ Lastly, a Mendelian randomization study noted that common variants in the HMGR gene were associated with an LDLlowering effect and an increase in body mass index, insulin resistance, and type 2 diabetes, ${ }^{73}$ which further supports the

Table 4 Comparison of Outcomes in Statin Users and Nonusers in the Propensity Score-Matched Cohort

\begin{tabular}{|c|c|c|c|c|c|c|}
\hline$\overline{\text { Outcome }}$ & $\begin{array}{l}\text { Statin nonusers no. }(\%) \\
(n=3,351)\end{array}$ & $\begin{array}{l}\text { Statin users no. }(\%) \\
(n=3,351)\end{array}$ & Odds ratio & \multicolumn{2}{|c|}{$95 \%$ CI } & $\overline{p \text { value }}$ \\
\hline mellitus & $649(19.4)$ & $1037(30.9)$ & 1.87 & 1.67 & 2.01 & $<0.0001$ \\
\hline Diabetes mellitus with complications & $69(2.1)$ & $167(5.0)$ & 2.50 & 1.88 & 3.32 & $<0.0001$ \\
\hline Overweight/obese & $1456(43.4)$ & $1564(46.7)$ & 1.14 & 1.04 & 1.25 & 0.008 \\
\hline
\end{tabular}


Table 5 Comparison of Components of Diabetes Complications in Statin Users and Nonusers in the Propensity Score-Matched Cohort

\begin{tabular}{|c|c|c|c|}
\hline Components of diabetes complications & $\begin{array}{l}\text { Statin nonusers no. }(\%) \\
(n=3351)\end{array}$ & $\begin{array}{l}\text { Statin users no. }(\%) \\
(n=3351)\end{array}$ & $p$ value \\
\hline Uncontrolled diabetes and diabetes with hyperosmolar or ketotic coma & $43(1.3)$ & $111(3.3)$ & $<0.0001$ \\
\hline Diabetes with renal manifestations & $11(0.3)$ & $26(0.8)$ & 0.01 \\
\hline Diabetes with ophthalmic manifestations & $3(0.1)$ & $17(0.5)$ & 0.001 \\
\hline Diabetes with neurological manifestations & $17(0.5)$ & $43(1.3)$ & 0.001 \\
\hline Diabetes with peripheral circulation manifestations & $5(0.1)$ & $18(0.5)$ & 0.005 \\
\hline Diabetes with hypoglycemia & $5(0.1)$ & $9(0.3)$ & 0.42 \\
\hline Diabetes with unspecified complication & $3(0.1)$ & $10(0.3)$ & 0.09 \\
\hline
\end{tabular}

link between statins and a higher risk of diabetes and obesity, and demonstrates that this is an "on-target" effect. ${ }^{74}$ Our study offers additional evidence for the association between statins and overweight/obesity, utilizing retrospective cohort observational data.

Our findings will need to be confirmed by other studies, as they may have significant implications. Our results indicate that extrapolating information from carefully selected patients in short-term randomized controlled studies to decades of statin use for primary prevention might not be appropriate. Additionally, statin effects on overall comorbidity, not only cardiovascular morbidity, need to become part of the risk/ benefit assessment.

The purpose of our study was not to examine whether the increased risk of diabetes and its complications among statin users is outweighed by the reduced risk of atherosclerotic cardiovascular disease. Comparing risks of cardiovascular disease between statin users and nonusers in observational data may be subject to confounding by indication - that is, statin users were prescribed statins because they may have had a family history of premature cardiovascular disease, high CRP, or increasing lipid profiles over time. Some investigators have suggested doubling the observed risks to account for this bias. ${ }^{75}$ Moreover, to appropriately account for the risk of cardiovascular disease in statin users and nonusers, both groups should be matched on lipid profile and blood pressure measurements and on Framingham or other cardiovascular risk score. This information was missing for most of our patients, and therefore our results cannot be used to examine the value of statins in primary prevention among healthy adults. Rather, they only indicate that short-term clinical studies may not fully describe the effects of statins in long-term real life utilization for primary prevention, and hence additional research utilizing prospective observational and pragmatic studies is needed. Our study also indicates that in order to examine the effects of statins in primary prevention, a measure for overall comorbidity must be developed and utilized in reporting the benefits, rather than depending entirely on total cardiovascular mortality and morbidity.

Our study has several limitations, including its retrospective observational design, which may suffer from unrecognized confounding factors despite our best effort to identify confounders. Additionally, our study used ICD-9-CM codes of AHRQ-CCS, which may lack sensitivity toward some variables such as smoking and overweight/obesity. We also lacked data on body mass index, $\mathrm{HbA}_{1 \mathrm{c}}$, serum creatinine, and urinalysis, all of which are important in supporting our outcomes. Although the use of ICD-9 codes in extracting diagnoses of diabetes with and without complications has good sensitivity and excellent specificity, we are not aware that using AHRQCCS codes was specifically validated in Tricare data. The use of ICD-9 codes to identify obesity as an outcome has low sensitivity but high specificity, which is another limitation to our study. However, the proportions of patients identified as overweight or obese in our outcome were similar to national trends; this may be due to the comprehensive longitudinal database, complete follow-up, easy and equal access to care within the military health care system, and the mandated routine visits for military personnel. It should be also noted that body mass index may not be reliable in identifying overweight/obesity in athletic and military populations. ${ }^{76,77}$ Determining baseline characteristics based on ICD-9 codes was another limitation, given the variable sensitivity and specificity of each disease group. However, we are not aware of any reason for differential ascertainment bias between statin users and nonusers (i.e., underestimation or overestimation is likely to affect both treatments equally). First, both statin users and nonusers had extensive continuous follow-up for almost 7 years and a mean number of $>60$ visits (despite being a healthy population). Second, the Tricare Prime/Plus health care system has unique features that offer easy and ample access to health care, and specific aspects of health care are mandated; therefore, there was ample chance to capture diseases. Third, controlling for the number of medical encounters

Table 6 Comparison of Outcomes in High-Intensity Statin Users Versus Moderate/Low-Intensity Statin Users

\begin{tabular}{|c|c|c|c|c|c|c|}
\hline \multirow{2}{*}{$\begin{array}{l}\text { Outcomes } \\
\text { Diabetes mellitus }\end{array}$} & \multirow{2}{*}{$\begin{array}{c}\begin{array}{l}\text { High-intensity statin users } \\
\text { no. }(\%)(\boldsymbol{n}=\mathbf{1 1 5 5})\end{array} \\
454(39.3)\end{array}$} & \multirow{2}{*}{$\begin{array}{l}\begin{array}{l}\text { Moderate/low-intensity statin } \\
\text { users no. }(\mathbf{\%})(\boldsymbol{n}=\mathbf{2 8 2 7})\end{array} \\
839(29.7)\end{array}$} & \multirow{2}{*}{$\begin{array}{c}\begin{array}{l}\text { Adjusted } \\
\text { odds ratio }^{\mathbf{a}}\end{array} \\
1.50\end{array}$} & \multicolumn{2}{|c|}{$95 \%$ CI } & \multirow{2}{*}{$\begin{array}{l}p \text { value } \\
0.0001\end{array}$} \\
\hline & & & & 1.30 & 1. & \\
\hline Diabetes mellitus wi & $95(8.2)$ & 119 (4.2) & 1.97 & 1.49 & 2.61 & 0.0001 \\
\hline Overweight/obese & $632(54.7)$ & $1219(43.1)$ & 1.61 & 1.40 & 1.84 & 0.0001 \\
\hline
\end{tabular}

${ }^{a}$ Adjusted for propensity score 
Table 7 Secondary and Sensitivity Analyses of Outcomes in Statin Users and Nonusers

\begin{tabular}{|c|c|c|c|c|c|c|}
\hline Outcome & Statin nonusers & Statin users & Adjusted odds ratio ${ }^{a}$ & \multicolumn{2}{|c|}{$95 \%$ CI } & $p$ value \\
\hline \multicolumn{7}{|c|}{ Healthy cohort (21,988 nonusers and 3982 statin users) } \\
\hline Diabetes mellitus & $2421(11.0)$ & $1293(32.5)$ & 2.11 & 1.92 & 2.32 & $<0.001$ \\
\hline Diabetes mellitus with complications & $213(1.0)$ & $214(5.4)$ & 2.78 & 2.18 & 3.53 & $<0.001$ \\
\hline Overweight/obese & $8608(39.2)$ & $1851(46.5)$ & 1.22 & 1.13 & 1.33 & $<0.001$ \\
\hline \multicolumn{7}{|c|}{ High-intensity statin-users cohort (21,988 nonusers and 1155 statin users) } \\
\hline Diabetes mellitus & $2421(11.0)$ & $454(39.3)$ & 2.55 & 2.21 & 2.94 & $<0.001$ \\
\hline Diabetes mellitus with complications & $213(1.0)$ & $95(8.2)$ & 3.68 & 2.70 & 5.00 & $<0.001$ \\
\hline Overweight/obese & $8608(39.2)$ & $632(54.7)$ & 1.58 & 1.34 & 1.80 & $<0.001$ \\
\hline \multicolumn{7}{|c|}{ Two-year statin-user cohort (21,988 nonusers and 3308 statin users) } \\
\hline Diabetes mellitus & $2421(11.0)$ & $1120(33.9)$ & 2.16 & 1.95 & 2.40 & $<0.001$ \\
\hline Diabetes mellitus with complications & $213(1.0)$ & $184(5.6)$ & 2.60 & 2.01 & 3.35 & $<0.001$ \\
\hline Overweight/obese & $8608(39.2)$ & $1552(46.9)$ & 1.24 & 1.14 & 1.35 & $<0.001$ \\
\hline \multicolumn{7}{|c|}{ Four-year statin-user cohort ( 21,988 nonusers and 2933 statin users) } \\
\hline Diabetes mellitus & $2421(11.0)$ & $1028(35.0)$ & 2.24 & 2.01 & 2.49 & $<0.001$ \\
\hline Diabetes mellitus with complications & $213(1.0)$ & $169(5.8)$ & 2.71 & 2.08 & 3.52 & $<0.001$ \\
\hline Overweight/obese & $8608(39.2)$ & $1373(46.8)$ & 1.22 & 1.11 & 1.33 & $<0.001$ \\
\hline \multicolumn{7}{|c|}{ Overweight/obesity incident cohort $(20,176$ nonusers and 3415 statin users $)$} \\
\hline Diabetes mellitus & $2045(10.1)$ & $1060(31.0)$ & 2.14 & 1.92 & 2.37 & $<0.001$ \\
\hline Diabetes mellitus with complications & $169(0.8)$ & $159(4.7)$ & 2.87 & 2.17 & 3.79 & $<0.001$ \\
\hline Overweight/obese & $7078(35.1)$ & $1371(40.1)$ & 1.26 & 1.16 & 1.38 & $<0.001$ \\
\hline
\end{tabular}

${ }^{a}$ Adjusted for propensity score

during the follow-up period did not significantly change our results. Fourth, as demonstrated in Table 1, nonusers actually had higher proportions of obesity at baseline. Lastly, the prevalence of overweight/obesity and diabetes were similar to recently published national trends, ${ }^{58,69}$ suggesting that the magnitude of underestimation was not sizable. Another limitation is that ICD-9-CM codes do not provide information on severity of illness. Therefore, it may be assumed that physicians were more biased to prescribe statins in patients with more severe overweight/obesity at baseline, and consequently, statin users were more to likely to develop diabetes and diabetic complications. However, such bias, if it existed, is unlikely to be responsible for an approximately twofold increase in the odds of diabetes incidence and a threefold increase in the odds of diabetic complications. The use of pharmacy data to account for medication use assumes, but cannot ascertain, that patients are actually taking their medications. However, approximately $73 \%$ of our statin users filled their statin prescriptions for 4 years, which may be considered a surrogate marker for actual use of medications. The pattern of statin use in our study, where $77 \%$ of statin users used simvastatin, may be different from current statin utilization trends. Data from the private sector indicate that the use of atorvastatin in certain markets may be as high as $48 \%$, and that rosuvastatin use has risen to $65 \%$ in some markets. ${ }^{78,79}$ Since using OR rather than relative risk (RR) may exaggerate the perception of risk, we calculated the RR of the outcomes using a previously published formula $^{80}$ as follows: $\mathrm{RR}$ of diabetes $=1.60$, diabetes with complications $=1.90$, and overweight/obesity $=1.07$.

In conclusion, statin use was associated with increased likelihood of patients being diagnosed with diabetes and of diabetic complications and overweight/obesity. Further investigations, including randomized controlled studies for prolonged periods and larger-scale prospective studies, are needed in order to obtain a more complete risk/benefit assessment of statin therapy for primary prevention.
Conflict of Interest: The authors declare that they do not have a conflict of interest.

CRF was supported by the US National Institutes of Health (NIH) in the form of a NIH/KL2 career development award (RRO25766) during the conduct of this study. In addition, CRF's institution has received research grants within the last 3 years from Bristol-Myers Squibb, Forest Labs, and Pfizer for CRF's research.

Dr. Mortensen was supported in part by a grant from the Agency for Healthcare Research and Quality (R24 HSO22418) and the University of Texas Southwestern Center for Patient-Centered Outcomes Research.

Funding Source: No funding was provided for the conduct of this study. This material is the result of work supported with resources and the use of facilities at the VA North Texas Health Care System and the University of Texas Southwestern.

Disclaimer: The views expressed herein are those of the authors and do not reflect the official policy or position of the Brooke Army Medical Center, the Department of the Army, Department of Defense, Department of Veterans Affairs, or the US government. The authors are employees of the US government. This work was prepared as part of their official duties and, as such, there is no copyright to be transferred.

Corresponding Author: Ishak Mansi, M.D.; Department of MedicineVA North Texas Health System, 4500 S. Lancaster Rd \#111E, Dallas, TX, USA (e-mail: Ishak.mansi@va.gov).

\section{REFERENCES}

1. Sattar N, Preiss D, Murray HM, et al. Statins and risk of incident diabetes: a collaborative meta-analysis of randomised statin trials. Lancet. 2010;375:735-42.

2. Sugiyama T, Tsugawa Y, Tseng CH, Kobayashi Y, Shapiro MF. Different time trends of caloric and fat intake between statin users and nonusers among us adults: gluttony in the time of statins? JAMA Intern Med. 2014; 174: 1038-45.

3. Redberg RF. Statins and weight gain. JAMA Intern Med. 2014;174:1046.

4. Nakata M, Nagasaka S, Kusaka I, Matsuoka H, Ishibashi S, Yada T. Effects of statins on the adipocyte maturation and expression of glucose transporter 4 (SLC2A4): implications in glycaemic control. Diabetologia. 2006;49:1881-92.

5. Colhoun HM, Betteridge DJ, Durrington PN, et al. Primary prevention of cardiovascular disease with atorvastatin in type 2 diabetes in the collaborative atorvastatin diabetes study (CARDS): multicentre randomised placebo-controlled trial. Lancet. 2004;364:685-96. 
6. Holman RR, Paul S, Farmer A, et al. Atorvastatin in factorial with omega3 EE90 risk reduction in diabetes (AFORRD): a randomised controlled trial. Diabetologia. 2009;52:50-9.

7. Liew SM, Lee PY, Hanafi NS, et al. Statins use is associated with poorer glycaemic control in a cohort of hypertensive patients with diabetes and without diabetes. Diabetol Metab Syndr. 2014;6:53.

8. Sukhija R, Prayaga S, Marashdeh M, et al. Effect of statins on fasting plasma glucose in diabetic and nondiabetic patients. J Investig Med. 2009;57:495-9.

9. Sever PS, Dahlof B, Poulter NR, et al. Prevention of coronary and stroke events with atorvastatin in hypertensive patients who have average or lower-than-average cholesterol concentrations, in the anglo-scandinavian cardiac outcomes trial-lipid lowering arm (ASCOT-LLA): a multicentre randomised controlled tria. Lancet. 2003;361:1149-58.

10. Officers A, Coordinators for the ACRGTA, Lipid-Lowering Treatment to Prevent Heart Attack T. Major outcomes in moderately hypercholesterolemic, hypertensive patients randomized to pravastatin vs usual care: the antihypertensive and lipid-lowering treatment to prevent heart attack trial (ALLHAT-LLT). JAMA. 2002;288:2998-3007.

11. Shepherd J, Cobbe SM, Ford I, et al. Prevention of coronary heart disease with pravastatin in men with hypercholesterolemia. West of Scotland coronary prevention study group. N Engl J Med. 1995;333:1301-7.

12. Ridker PM, Pradhan A, MacFadyen JG, Libby P, Glynn RJ. Cardiovascular benefits and diabetes risks of statin therapy in primary prevention: an analysis from the JUPITER trial. Lancet. 2012;380:565-71.

13. Guide for DoD Researchers on Using MHS Data. Office of the Assistant Secretary of Defense for Health Affairs (OSAD(HA)) TRICARE Management Activity (TMA) Human Research Protection Program (HRPP). October 10, 2012. available at: http://www.tricare.mil/tma/privacy/hrpp (last accessed March 16, 2015).

14. Luhrman S, Lehr E, Hefflin C, Saund N. Interface Control Document Describing the Case Management Exchange from BEA to MDR and M2 Baseline. DHSS program management. August 18, 2008 ed. Falls Church, VA DHSS; 2008.

15. Clinical Classifications Software (CCS) for ICD-9-CM [database on the Internet]. U.S. Agency for Healthcare Research and Quality. 2012 [cited 01/01/2012]. Available from: http://www.hcup-us.ahrq.gov/ toolssoftware/ccs/ccs.jsp (last accessed March 16, 2015).

16. Selim AJ, Fincke G, Ren XS, et al. Comorbidity assessments based on patient report: results from the veterans health study. J Ambul Care Manag. 2004;27:281-95.

17. Deyo RA, Cherkin DC, Ciol MA. Adapting a clinical comorbidity index for use with ICD-9-CM administrative databases. J Clin Epidemiol. 1992;45:613-9.

18. Stone NJ, Robinson JG, Lichtenstein AH, et al. 2013 ACC/AHA guideline on the treatment of blood cholesterol to reduce atherosclerotic cardiovascular risk in adults: a report of the American College of Cardiology/American Heart Association Task Force on Practice Guidelines. Circulation. 2014;129:S1-45.

19. Cowen ME, Dusseau DJ, Toth BG, Guisinger C, Zodet MW, Shyr Y. Casemix adjustment of managed care claims data using the clinical classification for health policy research method. Med Care. 1998;36:1108-13.

20. Duffy S, Elixhauser A, Sommers J. Diagnosis and procedure combinations in hospital inpatient data. Healthcare Cost and Utilization Project (HCUP 3) Research Note 5. Rockville, MD: Agency for Health Care Policy and Research; 1996. AHCPR Pub. No. 96-0047. 1996.

21. Elixhauser A, McCarthy E. Clinical classifications for health policy research, version 2: Hospital inpatient statistics. Healthcare Cost and Utilization Project (HCUP 3) Research Note 1. Rockville, MD: Agency for Health Care Policy and Research; 1996. AHCPR Pub. No. 96 0017. 1996.

22. Elixhauser A, Steiner C, Whittington C. Clinical classifications for health policy research: Hospital inpatient statistics, 1995. Healthcare Cost and Utilization Project, HCUP 3 Research Note. Rockville, MD: Agency for Health Care Policy and Research; 1998. AHCPR Pub. No. 98-0049. 1998.

23. Elixhauser A, Steiner C. Healthcare Cost and Utilization Project (HCUP) Research Note. Rockville, MD: Agency for Health Care Policy and Research; 1999. AHCPR Pub. No. 99-0034. 1999.

24. Mansi I, Frei CR, Pugh MJ, Makris U, Mortensen EM. Statins and musculoskeletal conditions, arthropathies, and injuries. JAMA Intern Med. 2013;173:1-10

25. Mansi I, Frei CR, Pugh MJ, Mortensen EM. Psychologic disorders and statin use: a propensity score-matched analysis. Pharmacotherapy. 2013;33:615-26.
26. Thompson DA, Makary MA, Dorman T, Pronovost PJ. Clinical and economic outcomes of hospital acquired pneumonia in intra-abdominal surgery patients. Ann Surg. 2006;243:547-52.

27. Lilly SM, Mortensen EM, Frei CR, Pugh MJ, Mansi IA. Comparison of the risk of psychological and cognitive disorders between persistent and nonpersistent statin users. Am J Cardiol. 2014;114:1035-9.

28. Leuschen J, Mortensen EM, Frei CR, Mansi EA, Panday V, Mansi I. Association of statin use with cataracts: a propensity score-matched analysis. JAMA Ophthalmol. 2013;131:1427-34.

29. Liu M, McPeek Hinz ER, Matheny ME, et al. Comparative analysis of pharmacovigilance methods in the detection of adverse drug reactions using electronic medical records. J Am Med Inform Assoc. 2013;20:420-6.

30. Radley DC, Gottlieb DJ, Fisher ES, Tosteson AN. Comorbidity riskadjustment strategies are comparable among persons with hip fracture. J Clin Epidemiol. 2008;61:580-7.

31. Ash AS, Posner MA, Speckman J, Franco S, Yacht AC, Bramwell L. Using claims data to examine mortality trends following hospitalization for heart attack in medicare. Health Serv Res. 2003;38: 1253-62.

32. Robinson Jw. Regression tree boosting to adjust health care cost predictions for diagnostic mix. Health Serv Res. 2008;43:755-72.

33. Bynum JP, Rabins PV, Weller W, Niefeld M, Anderson GF, Wu AW. The relationship between a dementia diagnosis, chronic illness, medicare expenditures, and hospital use. J Am Geriatr Soc. 2004;52:187-94.

34. Chou LF. Estimating medical costs of gastroenterological diseases. World J Gastroenterol. 2004;10:273-8.

35. Cowen ME, Strawderman RL. Quantifying the physician contribution to managed care pharmacy expenses: a random effects approach. Med Care. 2002;40:650-61.

36. Cook CB, Tsui C, Ziemer DC, Naylor DB, Miller WJ. Common reasons for hospitalization among adult patients with diabetes. Endocr Pract. 2006; 12:363-70.

37. Fogerty MD, Abumrad NN, Nanney L, Arbogast PG, Poulose B, Barbul A. Risk factors for pressure ulcers in acute care hospitals. Wound Repair Regen. 2008; 16:11-8.

38. Washington R, Andrews R, Mutter R. Emergency Department Visits for Adults with Diabetes, 2010. HCUP Statistical Brief \#167. November 2013. Agency for Healthcare Research and Quality, Rockville, MD. Available at http://www.hcup-us.ahrq.gov/reports/statbriefs/sb 167.pdf (last accessed March 16, 2015).

39. Wier L, Witt E, Burgess J, Elixhauser A. Hospitalizations Related to Diabetes in Pregnancy, 2008. HCUP Statistical Brief \# 102. December 2010. Agency for Healthcare Research and Quality, Rockville, MD. http://www. hcup-us.ahrq.gov/reports/statbriefs/sb102.pdf (last accessed March 16, 2015).

40. One in 16 Women Hospitalized for Childbirth Has Diabetes: AHRQ News and Numbers, December 15, 2010. December 2010. Agency for Healthcare Research and Quality, Rockville, MD. http://archive.ahrq.gov/news/ newsroom/news-and-numbers/121510.html (last accessed March 16, 2015).

41. Fraze T, Jiang H, Burgess J. Hospital Stays for Patients with Diabetes, 2008. HCUP Statistical Brief \#93. August 2010. Agency for Healthcare Research and Quality, Rockville, MD. http://www.hcup-us.ahrq.gov/reports/statbriefs/sb93.pdf (last accessed March 16, 2015).

42. Hines A, Barrett M, Jiang H, Steiner C. Conditions With the Largest Number of Adult Hospital Readmissions by Payer, 2011. HCUP Statistical Brief \#172. April 2014. Agency for Healthcare Research and Quality, Rockville, MD. http://www.hcup-us.ahrq.gov/reports/statbriefs/sb172Conditions-Readmissions-Payer.pdf (last accessed March 16, 2015).

43. Elixhauser A, Steiner C, Harris DR, Coffey RM. Comorbidity measures for use with administrative data. Med Care. 1998;36:8-27.

44. Li B, Evans D, Faris P, Dean S, Quan H. Risk adjustment performance of Charlson and Elixhauser comorbidities in ICD-9 and ICD-10 administrative databases. BMC Health Serv Res. 2008;8:12.

45. Guan H, Li B, Saunders LD, et al. Assessing validity of ICD-9-CM and ICD-10 administrative data in recording clinical conditions in a unique dually coded database. Health Serv Res. 2008;43:1424-41.

46. Miller DR, Safford MM, Pogach LM. Who has diabetes? Best estimates of diabetes prevalence in the Department of Veterans Affairs based on computerized patient data. Diabetes Care. 2004;27(Suppl 2):B10-21.

47. Memtsoudis SG, Bombardieri AM, Ma Y, Walz JM, Chiu YL, Mazumdar M. Mortality of patients with respiratory insufficiency and adult respiratory distress syndrome after surgery: the obesity paradox. J Intensive Care Med. 2012;27:306-11.

48. Scott SK, Rabito FA, Price PD, et al. Comorbidity among the morbidly obese: a comparative study of 2002 U.S. hospital patient discharges. Surg Obes Relat Dis. 2006;2:105-11. 
49. Vila-Corcoles A, Ochoa-Gondar O, Llor C, Hospital I, Rodriguez T, Gomez A. Protective effect of pneumococcal vaccine against death by pneumonia in elderly subjects. Eur Respir J. 2005;26:1086-91.

50. Allareddy V, Rampa S, Anamali S, Lee MK, Allareddy V, Nalliah RP. Obesity and its association with comorbidities and hospital charges among patients hospitalized for dental conditions. J Investig Clin Dent. 2015.

51. Wier L, Encinosa W. Obesity in Children: Hospitalizations from 2000 to 2009. HCUP Statistical Brief \#138. July 2012. Agency for Healthcare Research and Quality, Rockville, MD. Available at http://www.hcup-us. ahrq.gov/reports/statbriefs/sb138.pdf (last accessed March 16, 2015).

52. Weiss A, Elixhauser A. Obesity-Related Hospitalizations, 2004 versus 2009. HCUP Statistical Brief \#137. July 2012. Agency for Healthcare Research and Quality. Rockville, MD. Available at http://www.hcup-us. ahrq.gov/reports/statbriefs/sb137.pdf (last accessed March 16, 2015).

53. Elixhauser A, Steiner C. Obese Patients in U.S. Hospitals, 2004. HCUP Statistical Brief \#20. December 2006. Agency for Healthcare Research and Quality, Rockville, MD. http://www.hcup-us.ahrq.gov/reports/statbriefs/ sb20.pdf (last accessed March 16, 2015)

54. Goff SL, Pekow PS, Markenson G, Knee A, Chasan-Taber L, Lindenauer PK. Validity of using ICD-9-CM codes to identify selected categories of obstetric complications, procedures and co-morbidities. Paediatr Perinat Epidemiol. 2012;26:421-9.

55. FDA Drug Safety Communication: New restrictions, contraindications, and dose limitations for Zocor (simvastatin) to reduce the risk of muscle injury. 2011. Available at: http://www.fda.gov/Drugs/DrugSafety/ucm256581. htm. (last accessed March 16, 2015).

56. Becker S, Ichino A. Estimation of average treatment effects based on propensity scores. Stata J. 2002;2:358-77.

57. Leuven E, Sianesi B. PSMATCH2: Stata module to perform full Mahalanobis and propensity score matching, common support graphing, and covariate imbalance testing. Version 4.0.5 ed2003.

58. National Diabetes Statistics Report: Estimates of Diabetes and Its Burden in the United States, 2014. US Department of Health and Human Services; Centers for Disease Control and Prevention. 2014. Available at: http:// www.cdc.gov/diabetes/pubs/statsreport14.htm (last accessed March 16, 2015). 2014

59. Dormuth CR, Filion KB, Paterson JM, et al. Higher potency statins and the risk of new diabetes: multicentre, observational study of administrative databases. BMJ. 2014;348:g3244.

60. Rothman KJ. Six persistent research misconceptions. J Gen Intern Med. 2014;29:1060-4.

61. Ruscica M, Macchi C, Morlotti B, Sirtori CR, Magni P. Statin therapy and related risk of new-onset type 2 diabetes mellitus. Eur J Intern Med. 2014;25:401-6.

62. Culver AL, Ockene IS, Balasubramanian R, et al. Statin use and risk of diabetes mellitus in postmenopausal women in the Women's Health Initiative. Arch Intern Med. 2012;172:144-52.

63. Chen CW, Chen TC, Huang KY, Chou P, Chen PF, Lee CC. Differential impact of statin on new-onset diabetes in different age groups: a population-based case-control study in women from an asian country. PLOS ONE. 2013;8:e71817.

64. Currie O, Mangin D, Williman J, McKinnon-Gee B, Bridgford P. The comparative risk of new-onset diabetes after prescription of drugs for cardiovascular risk prevention in primary care: a national cohort study. BMJ Open. 2013;3(11):e003475.

65. Preiss D, Seshasai SR, Welsh P, et al. Risk of incident diabetes with intensive-dose compared with moderate-dose statin therapy: a metaanalysis. JAMA. 2011;305:2556-64.

66. Nielsen SF, Nordestgaard BG. Statin use before diabetes diagnosis and risk of microvascular disease: a nationwide nested matched study. Lancet Diabetes Endocrinol. 2014;2:894-900.

67. Gordon B, Chang S, Kavanagh $\mathbf{M}$, et al. The effects of lipid lowering on diabetic retinopathy. Am J Ophthalmol. 1991;112:385-91.

68. Sen K, Misra A, Kumar A, Pandey RM. Simvastatin retards progression of retinopathy in diabetic patients with hypercholesterolemia. Diabetes Res Clin Pract. 2002;56:1-11.

69. Ng M, Fleming T, Robinson M, et al. Global, regional, and national prevalence of overweight and obesity in children and adults during 19802013: a systematic analysis for the Global Burden of Disease Study 2013. Lancet. 2014;384:766-81.

70. Aguirre L, Hijona E, Macarulla MT, et al. Several statins increase body and liver fat accumulation in a model of metabolic syndrome. J Physiol Pharmacol. 2013;64:281-8.

71. Lee DS, Markwardt S, Goeres L, et al. Statins and physical activity in older men: the osteoporotic fractures in men study. JAMA Intern Med 2014; 174:1263-70.
72. Maki KC, Ridker PM, Brown WV, Grundy SM, Sattar N. An assessment by the statin diabetes safety task force: 2014 update. J Clin Lipidol. 2014;8:S17-29.

73. Swerdlow DI, Preiss D, Kuchenbaecker KB, et al. HMG-coenzyme a reductase inhibition, type 2 diabetes, and bodyweight: evidence from genetic analysis and randomised trials. Lancet. 2015;385:351-61.

74. Frayling TM. Statins and type 2 diabetes: genetic studies on target. Lancet. 2015;385:310-2.

75. Cook NR, Ridker PM. Further insight into the cardiovascular risk calculator: the roles of statins, revascularizations, and underascertainment in the Women's Health Study. JAMA Intern Med. 2014;174:1964-71.

76. Haddock CK, Poston WS, Klesges RC, Talcott GW, Lando H, Dill PL. An examination of body weight standards and the association between weight and health behaviors in the United States Air Force. Mil Med. 1999;164:51-4.

77. Ode JJ, Pivarnik JM, Reeves MJ, Knous JL. Body mass index as a predictor of percent fat in college athletes and nonathletes. Med Sci Sports Exerc. 2007;39:403-9.

78. Teng JF, Gomes T, Camacho X, Grundy S, Juurlink DN, Mamdani MM. Impact of the JUPITER trial on statin prescribing for primary prevention. Pharmacotherapy. 2014;34:9-18.

79. Bazalo GR. Managed care trends in statin usage. Manag Care. 2001;10:48-50.

80. McNutt LA, Wu C, Xue X, Hafner JP. Estimating the relative risk in cohort studies and clinical trials of common outcomes. Am J Epidemiol. 2003; 157:940-3.

\section{APPENDIX}

\section{Table 8 AHRQ-CCS Disease Categories Excluded to Create a Healthy Cohort}

\begin{tabular}{ll}
\hline \hline Disease group name & $\begin{array}{l}\text { AHRQ-CCS } \\
\text { category } \\
\text { number }\end{array}$ \\
\hline
\end{tabular}

AHRQ-CCS categories that suggested the presence of cardiovascular diseases or their equivalents at baseline

Diabetes mellitus with and without complications 49 and 50

Heart valve disorders

Pericarditis, endocarditis, myocarditis, or

cardiomyopathy

Hypertension with complications and secondary

hypertension

Acute myocardial infarction

Coronary atherosclerosis and other heart disease

Pulmonary heart disease

Conduction disorders

Cardiac dysrhythmias

Cardiac arrest and ventricular fibrillation

Congestive heart failure; non-hypertensive

Acute cerebrovascular disease

Occlusion or stenosis of precerebral arteries

Other and ill-defined cerebrovascular disease

Transient cerebral ischemia

Peripheral and visceral atherosclerosis

Aortic; peripheral; and visceral artery aneurysms

Aortic and peripheral arterial embolism or hrombosis

AHRQ-CCS categories suggesting the presence of comorbid

conditions that might limit life expectancy or physical activity

Chronic obstructive pulmonary disease and

bronchiectasis

Respiratory failure; insufficiency; arrest in adult $\quad 131$

Nephritis; nephrosis; renal sclerosis 156

Chronic kidney disease $\quad 158$

Rheumatoid arthritis and related disease $\quad 202$

Pathological fracture $\quad 207$

Systemic lupus erythematosus and connective 210

tissue disorders

Schizophrenia and other psychotic disorders 659

Suicide and intentional self-inflicted injury

AHRQ-CCS Agency for Health Research and Quality Clinical Classifications Software 
Table 9 Outcome Groups and Their Definitions

\begin{tabular}{ll}
\hline \hline Group name & ICD-9-CM codes \\
\hline Diabetes mellitus without & $24900,25000,25001,7902$, \\
complication (AHRQ-CCS & $79021,79022,79029,7915$, and \\
category 49) & $7916 ;$ excluding codes V4585, \\
& V5391, V6546 \\
Diabetes mellitus with & $24901,24910,24911,24920$, \\
complications (AHRQ-CCS & $24921,24930,24931,24940$, \\
category 50) & $24941,24950,24951,24960$, \\
& $24961,24970,24971,24980$, \\
& $24981,24990,24991,25002$, \\
& $25003,25010,25011,25012$, \\
& $25013,25020,25021,25022$, \\
& $25023,25030,25031,25032$, \\
& $25033,25040,25041,25042$, \\
& $25043,25050,25051,25052$, \\
& $25053,25060,25061,25062$, \\
& $25063,25070,25071,25072$, \\
& $25073,25080,25081,25082$, \\
& $25083,25090,25091,25092$, \\
abesity (selected ICD-9-CM codes & $2780,27800,27801,27802$, \\
from AHRQ-CCS category 56 & $27803,2781,2788$, and 7831. \\
[other nutritional; endocrine; and & \\
metabolic disorders]) &
\end{tabular}

AHRQ-CCS Agency for Health Research and Quality Clinical Classifications Software
Table 10 Definitions of Baseline Characteristics ${ }^{\mathrm{a}}$

Disease group AHRQ-CSS

category

Alcohol-related disorders

Substance-related disorders

Category 660

Category 661

Category 98

Category 157

Category 128

Category 153

Category 140

Category 102

Category 104

Categories 203, 204, 205

Nonspecific chest pain

Heart disease not otherwise specified

Osteoarthritis, arthropathy, and back

disorder

Sprains, strains, and trauma-related joint

disorders

Fracture of bone

Categories 225, 232

Categories 226, 229, 230, 231

Osteoporosis

Rehabilitation care; fitting of prostheses

Category 206

Category 254

and adjustment of devices

AHRQ-CCS Agency for Health Research and Quality Clinical Classifications Software ${ }^{I 1}$

${ }^{a}$ Diagnosis is based on ICD-9-CM codes as identified in respective disease category of AHRQ-CCS 